\title{
Development of nutritional iron deficiency in growing male rats: haematological parameters, iron bioavailability and oxidative defence
}

\author{
María J. M. Alférez*, Javier Díaz-Castro, Inmaculada López-Aliaga, María Rodríguez-Ferrer, \\ Luis Javier Pérez-Sánchez and Margarita S. Campos \\ Department of Physiology, Faculty of Pharmacy, University of Granada and Institute of Nutrition and Food Technology, \\ Granada 18071, Spain
}

(Received 12 July 2010 - Revised 3 August 2010 - Accepted 24 August 2010 - First published online 8 October 2010)

\section{Abstract}

Despite Fe deficiency having been widely studied, the sequence of events in its development still remains unclear. The aim of the present study was to elucidate the effects of nutritional Fe-deficiency development on haematological parameters, Fe bioavailability and the enzymes involved in oxidative defence in recently weaned male Wistar albino rats. Control (C) and Fe-deficient (ID) groups were fed the AIN-93 G diet with a normal Fe level $(45 \mathrm{mg} / \mathrm{kg}$ diet $)$ or with a low Fe level $(5 \mathrm{mg} / \mathrm{kg}$ diet), respectively, for 20 , 30 or $40 \mathrm{~d}$. At day 20 serum Fe, serum ferritin and the saturation of transferrin decreased drastically, decreasing further in the course of Fe-deficiency development for the saturation of transferrin. The development of Fe deficiency did not affect plasma thiobarbituric acid-reactive substance production, or catalase (CAT) and glutathione peroxidase (GPx) activities in erythrocyte cytosol. Fe deficiency diminished hepatic Fe content and CAT and GPx activities in hepatic cytosol only at day the 20. However, in spite of the minor Fe deposits in the brain of ID rats, the CAT and GPx activities in the brain cytosolic fraction did not differ in any of the studied periods $v$. control rats. These results show that brain is a tissue that does not seem to depend on Fe levels for the maintenance of antioxidant defence mechanisms in the course of nutritional Fe deficiency.

Key words: Iron-deficiency development: Oxidative defence: Liver and brain: Growing rats

Infants aged 6-24 months constitute one of the groups at highest risk of $\mathrm{Fe}$ deficiency ${ }^{(1)}$. Fe requirements are most likely to exceed $\mathrm{Fe}$ intake at two time periods in the lifecycle: the first 6-18 months of postnatal life and then, for girls, during adolescence. Fe deficiency during the first year of life occurs at a time point of rapid neural development, and when morphological, biochemical and bioenergetic alterations may all influence future functioning $^{(2,3)}$. Fe deficiency has been considered an important risk factor for ill health ${ }^{(4)}$. Fe status in infancy is determined by four main factors ${ }^{(1,5)}$ : the Fe the infant is born with (which is related to maternal Fe status), the infant's postnatal needs for $\mathrm{Fe}$, the external sources of bioavailable $\mathrm{Fe}$ and $\mathrm{Fe}$ losses. Fe is essential for all tissues in a young child's developing body ${ }^{(6)}$. The brain is the most vulnerable during critical periods of development ${ }^{(7)}$. Fe is present in the brain from very early in life, when it participates in the neural myelination processes ${ }^{(8,9)}$, learning and interacting behaviours $^{(10)}$, and it is necessary by enzymes involved in the synthesis of the neurotransmitters serotonin (tryptophan hydroxylase) and dopamine (tyrosine hydroxylase) ${ }^{(11)}$. There is scant information available on the influence of Fe-deficiency development over enzymes related to oxidative defence. The objective of present study was to investigate the development of nutritional Fe deficiency (20,30 or $40 \mathrm{~d}$ ) in the early stages of life on oxidative defence in tissues such as the brain and liver in growing male rats. Moreover, in the present study, haematological parameters and $\mathrm{Fe}$ bioavailability were also investigated in order to know how Fe status changes during the induction of Fe deficiency.

\section{Materials and methods}

\section{Animals}

In the present study, forty-eight male Wistar albino rats, aged 3 weeks weighing about $40-46 \mathrm{~g}$, purchased from the University of Granada Laboratory Animal Service were used. Animal care procedures and experimental protocols were approved by the Ethics Committee of the

Abbreviations: ADC, apparent digestibility coefficient; CAT, catalase; ID, Fe deficient; GPx, glutathione peroxidase; SOD, superoxide dismutase; TRARS, thiobarbituric acid-reactive substances. 
University of Granada in accordance with European Community guidelines.

\section{Experimental design and diets}

The rats were randomly divided into six groups: three control groups (C) and three Fe-deficient groups (ID) receiving the AIN-93G diet $^{(12)}$ with a normal Fe level (45 mg Fe/kg diet) or with a low Fe level $(5 \mathrm{mg} \mathrm{Fe} / \mathrm{kg} \mathrm{diet})^{(13)}$, respectively, for 20, 30 or $40 \mathrm{~d}$.

From the start of the study, the rats were maintained in an environment of controlled temperature $\left(21-23^{\circ} \mathrm{C}\right)$, humidity (55\%) and light-dark cycle (12 h-12 h), with ad libitum food and mineral-free water available. The last $7 \mathrm{~d}$ of the different periods of the study (from days 13 to 20, 23 to 30 and 33 to 40), records of weight, food intake, and urine and faeces were collected daily. On days 20,30 or 40 , the rats were fasted overnight and then anaesthetised by intraperitoneal injection of $5 \mathrm{mg}$ sodium pentobarbital $/ 100 \mathrm{~g}$ body weight (Sigma, St Louis, MO, USA). After median laparatomy, the rats were totally bled by cannulation of the abdominal aorta and aliquots with EDTA were analysed to measure the haematological parameters and the rest of the blood was centrifuged $\left(1500 \mathrm{~g}, 4^{\circ} \mathrm{C}, 15 \mathrm{~min}\right)$ to measure thiobarbituric acid-reactive substances (TBARS) and superoxide dismutase (SOD) activity. The remaining blood was centrifuged without anticoagulant at $1500 \mathrm{~g}$ for $15 \mathrm{~min}$ at $4^{\circ} \mathrm{C}$ to separate the cells from the serum for subsequent analysis of Fe, ferritin and total Fe-binding capacity. The liver and brain (which were split in two portions, one to measure the Fe content and the rest to measure enzyme activity) were removed, washed with ice-cold saline solution $(0.9 \%, \mathrm{w} / \mathrm{v}$, $\mathrm{NaCl}$ ) and stored immediately at $-40^{\circ} \mathrm{C}$ until Fe analysis. Brain, liver and erythrocyte cytosolic fraction were prepared by differential centrifugation by hypotonic haemolysis according to the method described by Hanahan \& Ekholm ${ }^{(14)}$, preserving the cytosol fraction at $-80^{\circ} \mathrm{C}$ for further analyses. The final fractions were aliquoted, snapfrozen in liquid $\mathrm{N}_{2}$ and stored at $-80^{\circ} \mathrm{C}$ until analysis. Cytosolic protein contents were measured as described previously $^{(15)}$. The activity of the antioxidant enzymes catalase (CAT) and glutathione peroxidase (GPx) in the brain, liver and erythrocyte cytosol was measured.

\section{Analytical procedures}

All the reagents were of analytical grade, and ultrapure water of $18 \mathrm{M} \Omega \mathrm{cm}$ specific resistivity was obtained from a Milli-Q purification system (Millipore Corporation, Billerica, MA, USA).

\section{$D M$}

Moisture contents of the diet were determined by drying the materials in an oven at $105 \pm 2{ }^{\circ} \mathrm{C}$ until the weight remained constant (approximately $48 \mathrm{~h}$ ).

\section{Iron determination}

Fe concentrations in the diets, faeces, urine, liver and brain were determined by atomic absorption spectrophotometry (Perkin-Elmer Analyst 1100B spectrometer with WinLab32 for AA software, Ueberlingen, Germany). The samples had been previously mineralised by the wet method in a sand bath (J.R. SELECTA, Barcelona, Spain). Samples of lyophilised bovine liver (certified reference material BCR 185; Community Bureau of References, Brussels, Belgium) were simultaneously used to check the Fe recovery (Fe value $=210(\operatorname{sem} 6 \cdot 0) \mathrm{mg} / \mathrm{kg}$, mean (SEM) of five determinations, certified value $214(\operatorname{sem} 5 \cdot 0) \mathrm{mg} / \mathrm{kg}$ ).

\section{Haematological test}

Erythrocytes, mean corpuscular volume, mean corpuscular $\mathrm{Hb}$, platelets and $\mathrm{Hb}$ in blood samples were measured by using an automated haematology analyser (Sysmex KX-21, Tokyo, Japan). Serum ferritin concentration was determined using the Rat Ferritin ELISA Kit (Biovendor Gmbh, Heidelberg, Germany). To calculate the rate of transferrin saturation, total Fe-binding capacity and serum Fe levels were determined colorimetrically and enzymatically using Sigma Diagnostics Iron and Total Iron-Binding Capacity reagents (Sigma Diagnostics). The rate of transferrin saturation was subsequently calculated using the following equation:

$$
\begin{aligned}
\text { Transferrin saturation }(\%) & \\
= & \operatorname{serum} \text { Fe concentration }(\mu \mathrm{g} / \mathrm{l}) / \text { total Fe } \\
& \text {-binding capacity }(\mu \mathrm{g} / \mathrm{l}) \times 100 .
\end{aligned}
$$

\section{Thiobarbituric acid-reactive substance measurement}

The extent of lipid peroxidation was evaluated in plasma by measuring the concentration of TBARS according to the methods described by Yagi ${ }^{(16)}$ and Ohkawa et al. ${ }^{(17)}$. Plasma ( $1 \mathrm{ml}$ ) was mixed with $1 \mathrm{ml}$ of $15 \%$ TCA (SigmaAldrich) and centrifuged at $80 \boldsymbol{g}$ for $10 \mathrm{~min}$. Supernatant ( $1 \mathrm{ml}$ ) was mixed with $1 \mathrm{ml}$ of tetrabutylammonium reagent $(0.67 \%)$ and the mixture was kept in a boiling water-bath for $20 \mathrm{~min}$. The reaction product was extracted and measured by spectrophotometric analysis (Thermo Spectronic, Rochester, NY, USA) at $532 \mathrm{~nm}$. The assay procedure was calibrated using tetraethoxypropanone (SigmaAldrich) as a malodialdehyde source. The results were expressed as nmol TBARS per mg proteins.

\section{Catalase activity}

CAT activity was determined by following Aebi's method ${ }^{(18)}$, by monitoring at $240 \mathrm{~nm}$ the $\mathrm{H}_{2} \mathrm{O}_{2}$ decomposition, as a consequence of the catalytic activity of CAT. The activity was calculated from the first-order rate constant $K(1 / \mathrm{s})$. 
Table 1. Haematological parameters in control (C) and iron-deficient (ID) rats* (Mean values with their standard errors)

\begin{tabular}{|c|c|c|c|c|c|c|c|c|c|c|c|c|c|c|c|c|c|}
\hline & \multicolumn{17}{|c|}{ Fe-deficiency effect $(n 48)$} \\
\hline & \multicolumn{5}{|c|}{ Day $20(n 16)$} & \multicolumn{5}{|c|}{ Day $30(n 16)$} & \multicolumn{5}{|c|}{ Day $40(n 16)$} & & \\
\hline & \multicolumn{2}{|c|}{$C(n 8)$} & \multicolumn{2}{|c|}{$\mathrm{ID}(n 8)$} & \multirow[b]{2}{*}{$P$} & \multicolumn{2}{|c|}{$C(n 8)$} & \multicolumn{2}{|c|}{ ID $(n 8)$} & \multirow[b]{2}{*}{$P$} & \multicolumn{2}{|c|}{$C(n 8)$} & \multicolumn{2}{|c|}{$\mathrm{ID}(n 8)$} & \multirow[b]{2}{*}{$P$} & \multicolumn{2}{|c|}{ Time effect } \\
\hline & Mean & SEM & Mean & SEM & & Mean & SEM & Mean & SEM & & Mean & SEM & Mean & SEM & & $C(n 24)$ & ID $(n 24)$ \\
\hline $\begin{array}{l}\mathrm{Hb} \\
\text { concentration (g/l) }\end{array}$ & 123 & 6 & $99^{A}$ & 3 & 0.001 & $116^{\mathrm{a}}$ & 7 & $85^{\mathrm{B}}$ & 4 & 0.0002 & 126 & 4 & $72^{C}$ & 2 & 0.0001 & NS & 0.01 \\
\hline Haematocrit (\%) & $46 \cdot 3$ & 2.5 & $26 \cdot 2$ & 1.3 & 0.001 & $47 \cdot 6$ & 3.3 & 28.9 & 1.7 & 0.001 & $49 \cdot 6$ & $2 \cdot 4$ & 23.6 & 1.6 & 0.0001 & NS & NS \\
\hline $\begin{array}{l}\text { Erythrocytes } \\
\left(10^{12} / l\right)\end{array}$ & 6.5 & 0.4 & $5 \cdot 3^{A B}$ & 0.3 & 0.01 & 6.5 & 0.4 & $6 \cdot 0^{\mathrm{A}}$ & 0.3 & NS & $7 \cdot 7$ & 0.3 & $5 \cdot 1^{\mathrm{B}}$ & 0.2 & 0.001 & NS & 0.05 \\
\hline MCV (fl) & $71 \cdot 2$ & 3.0 & 49.1 & 0.8 & 0.001 & 73.4 & 0.6 & 48.3 & 1.0 & 0.001 & $72 \cdot 4$ & 0.9 & 48.8 & 1.3 & 0.001 & NS & NS \\
\hline $\mathrm{MCH}(\mathrm{pg})$ & 18.9 & 0.3 & $17.6^{\mathrm{A}}$ & 0.2 & 0.001 & $18 \cdot 1$ & 0.4 & $14 \cdot 7^{B}$ & 0.2 & 0.001 & 18.5 & 0.4 & $14.0^{\mathrm{B}}$ & 0.2 & 0.001 & NS & 0.001 \\
\hline Platelets $\left(10^{9} / \mathrm{l}\right)$ & $703^{a}$ & 66 & $1224^{\mathrm{C}}$ & 25 & 0.001 & $694^{\mathrm{a}}$ & 60 & $1336^{\mathrm{B}}$ & 17 & 0.0006 & $688^{\mathrm{a}}$ & 39 & $2026^{A}$ & 13 & 0.0001 & NS & 0.0001 \\
\hline Serum Fe $(\mu \mathrm{g} / \mathrm{l})$ & $1300^{\mathrm{a}}$ & 103 & 145 & 8 & 0.0001 & $903^{\mathrm{b}}$ & 95 & 164 & 10 & 0.0004 & $1200^{\mathrm{a}}$ & 99 & 181 & 18 & 0.0002 & 0.01 & NS \\
\hline TIBC $(\mu \mathrm{g} / \mathrm{l})$ & $4560^{a}$ & 110 & $7450^{\mathrm{C}}$ & 104 & 0.001 & $3840^{\mathrm{b}}$ & 151 & $10780^{\mathrm{B}}$ & 204 & 0.0003 & $3250^{c}$ & 98 & $14500^{\mathrm{A}}$ & 305 & 0.0001 & 0.001 & 0.0001 \\
\hline $\begin{array}{l}\text { Transferrin } \\
\quad \text { saturation (\%) }\end{array}$ & $29 \cdot 3^{\mathrm{b}}$ & 1.0 & $2 \cdot 0^{\mathrm{A}}$ & 0.01 & 0.0002 & $23.5^{c}$ & 1.0 & $1.6^{\mathrm{B}}$ & 0.01 & 0.0004 & $40 \cdot 3^{a}$ & 2.9 & $1.4^{\mathrm{C}}$ & 0.01 & 0.0001 & 0.01 & 0.001 \\
\hline $\begin{array}{l}\text { Serum } \\
\quad \text { ferritin }(\mu \mathrm{g} / \mathrm{l})\end{array}$ & $95 \cdot 7^{\mathrm{a}}$ & $6 \cdot 3$ & $25 \cdot 5^{\mathrm{A}}$ & $2 \cdot 5$ & 0.0003 & $78 \cdot 2^{b}$ & 3.7 & $23 \cdot 4^{\mathrm{A}}$ & $1 \cdot 1$ & 0.0006 & $80 \cdot 2^{b}$ & $2 \cdot 4$ & $19 \cdot 3^{\mathrm{B}}$ & $1 \cdot 7$ & 0.0001 & 0.01 & 0.05 \\
\hline
\end{tabular}

$\mathrm{MCV}$, mean corpuscular volume; $\mathrm{MCH}$, mean corpuscular $\mathrm{Hb}$; TIBC, total Fe-binding capacity.

${ }^{a, b, c}$ For the time effect, the mean values of $C$ groups within a row with unlike superscript letters were significantly different $(P \leq 0.05)$.

${ }^{A, B, C}$ For the time effect, the mean values of ID groups within a row with unlike superscript letters were significantly different $(P \leq 0.05)$.

*As there were no interactions between Fe deficiency (C or ID) and time (20,30 or 40), but there were significant main effects of Fe deficiency and significant main effects of time, the data were pooled to show pooled means for the main effects only. 


\section{Superoxide dismutase activity}

SOD activity was determined according to the method described by Crapo et al. ${ }^{(19)}$. It was based on the inhibition by SOD in the reduction of cytochrome $c$, measured by spectrophotometry at $550 \mathrm{~nm}$. One unit of SOD activity is defined as the amount of enzyme required to produce $50 \%$ inhibition of the rate of reduction of cytochrome $c$.

\section{Glutathione peroxidase activity assay}

GPx activity was measured using the technique of Flohé \& Gunzler ${ }^{(20)}$. This method is based on the instantaneous formation of oxidised glutathione during the reaction catalysed by GPx. This oxidised glutathione is continually reduced by an excess of glutathione reductase and NADPH present in the cuvette. The subsequent oxidation of NADPH to $\mathrm{NADP}^{+}$was monitored spectrophotometrically at $340 \mathrm{~nm}$. During the reaction, cumene hydroperoxide was used as a substrate.

\section{Biological indices}

The following indices were calculated from the data on Fe intake and faecal and urinary Fe excretion:

Apparent digestibility coefficient (ADC)

$$
\begin{aligned}
= & (\text { intake }- \text { faecal excretion }) \times 100 / \text { intake } ; \text { Balance } \\
= & (\text { intake }- \text { faecal excretion })-\text { urinary excretion; } \\
& R / I(\%)=\text { balance } \times 100 / \text { intake },
\end{aligned}
$$

where $R$ is the retention and $I$ is the intake.

\section{Statistical methods}

Statistical analyses were performed using the SPSS computer program (SPSS, version 15.0, 2008; SPSS, Inc., Chicago, IL, USA). Differences between groups C $v$. ID were tested for statistical significance with Student's $t$ test. Variance analysis by one-way methods was used to compare the different periods $(20,30$ or $40 \mathrm{~d})$ in the two groups of animals $\mathrm{C}$ and ID. Individual means were tested using pair-wise comparison with Tukey's multiple comparison test when main effects and interactions were significant. Data were analysed statistically by two-way ANOVA to determine the effects of Fe deficiency, the time $(20,30$ or $40 \mathrm{~d})$ and their interactions (Fe deficiency $\times$ time). The level of significance was set at $P<0 \cdot 05$. All the data are reported as mean values with their standard errors.

\section{Results}

The consumption of the Fe-restrictive diet provoked a decrease in $\mathrm{Hb}$ and haematocrit in all periods studied

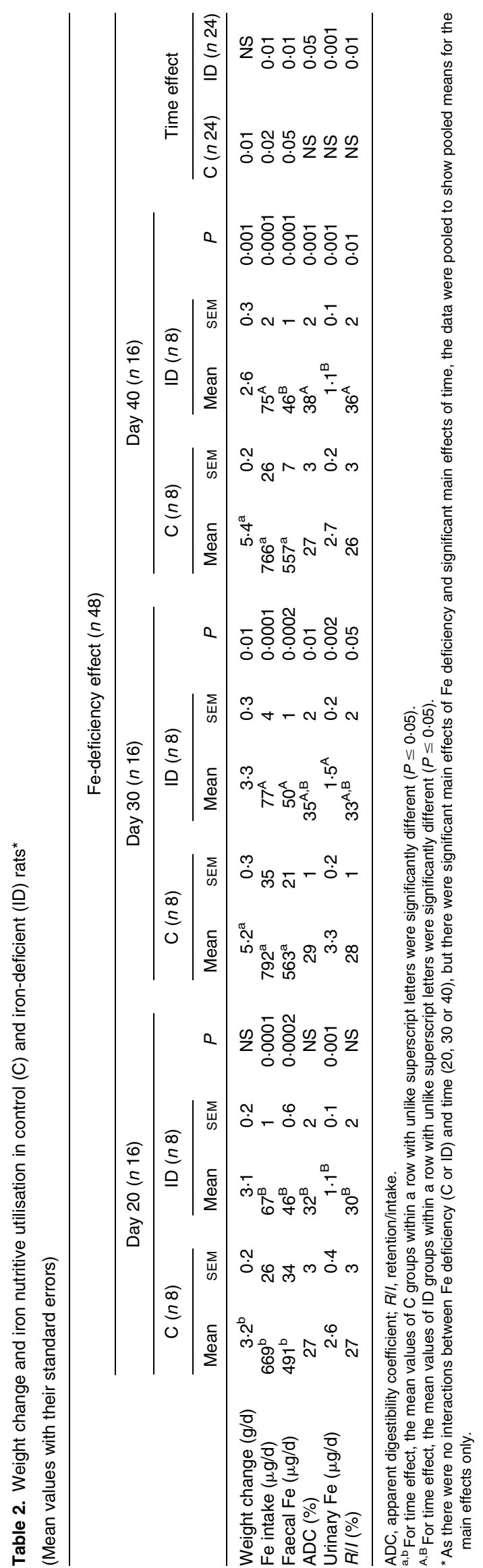


(significant level, Table 1), especially the decrease in haematocrit at day 40 , diminishing by $52 \%$ with regard to their counterparts $\mathrm{C}(P=0.0001)$. The $\mathrm{Hb}$ decrease became more pronounced in the ID group as the degree of Fe deficiency advanced, being significant when comparing the periods $30 v .40 \quad(P=0.048)$ and $20 v$ v. 40 ( $P=0.0012$ ), whereas the levels of haematocrit were kept low in the three studied periods, without significant differences between them. Likewise, the nutritional $\mathrm{Fe}$ deficiency diminished the erythrocytes in the three periods, being significant at day $20(P=0.009)$ and $40(P=0.0011)$, with regard to $C$ groups. In addition, in the course of the development of the Fe deficiency, the lowest erythrocyte count corresponds to day 40 compared with day 30 $(P=0.039)$. In relation to the erythrocytic indexes mean corpuscular volume and mean corpuscular $\mathrm{Hb}$, both diminished due to Fe deficiency $(P=0.001)$ during the three periods studied. In ID rats, the number of platelets increased in the three studied periods (significant level, Table 1), reaching values double that of the initial count at days 20 and 30 of supplying the Fe-restrictive diet and treble in day 40, with regard to the animals that received a diet with normal Fe content. As the Fe deficiency was established, there was an increase in the number of platelets, reaching values of 2026 (SEM 13) at day $40 v .1224$ (SEM $25)$ at day $20(P=0.0002)$. The reduced serum Fe of the ID group at day 20 (145 (SEM 8) $\mu \mathrm{g} / \mathrm{l})$ compared with that of the C group at the same time point (1300 (sem 103) $\mu \mathrm{g} / \mathrm{l})$ $(P<0.0001)$ is also noteworthy, values that remained low during the whole development of the Fe deficiency. In relation to the percentage saturation of transferrin, the drastic decrease in ID rats, which decreased further in the course of the development of the Fe deficiency (significant level, Table 1) is noteworthy. Percentage saturation of transferrin was 1.4 (SEM $0 \cdot 01$ ) at day 40 for the ID group, compared with 40.3 (SEM 2.9) for the C group $(P=0.0001)$. With regard to the levels of serum ferritin, in ID rats these were about a quarter of those in the $C$ rats in all three studied periods (significant level, Table 1).

Table 2 summarises the weight change and digestive and metabolic utilisation of Fe in both groups of animals. At the beginning of the experiment, the rats recently weaned with $21 \mathrm{~d}$ of age had a mean weight of 43.8 (SEM 3.5) g. On day 30 of the study, significant differences in the increase of weight between both groups of animals were observed, being lower in the ID group $(P=0.009)$, differences that were accentuated after $40 \mathrm{~d}$ of supplying the Fe-restrictive diet, diminishing the increase of weight in ID animals to half that of the $\mathrm{C}$ rats $(P=0 \cdot 0011)$. After $20 \mathrm{~d}$ of consuming a diet with a low Fe content, ID rats featured slightly higher values of digestive utilisation (ADC) and retention $(R / I)$ of this mineral with regard to their controls and the differences became higher as time of consumption of the Ferestrictive diet increased: $\operatorname{ADC}(P=0.01$ at day 30 and $P=0.0012$ at day 40$)$ and $R / I$ of $\mathrm{Fe}(P=0.0047$ at day 30 and $P=0.011$ at day 40$)$. In the course of the study, the

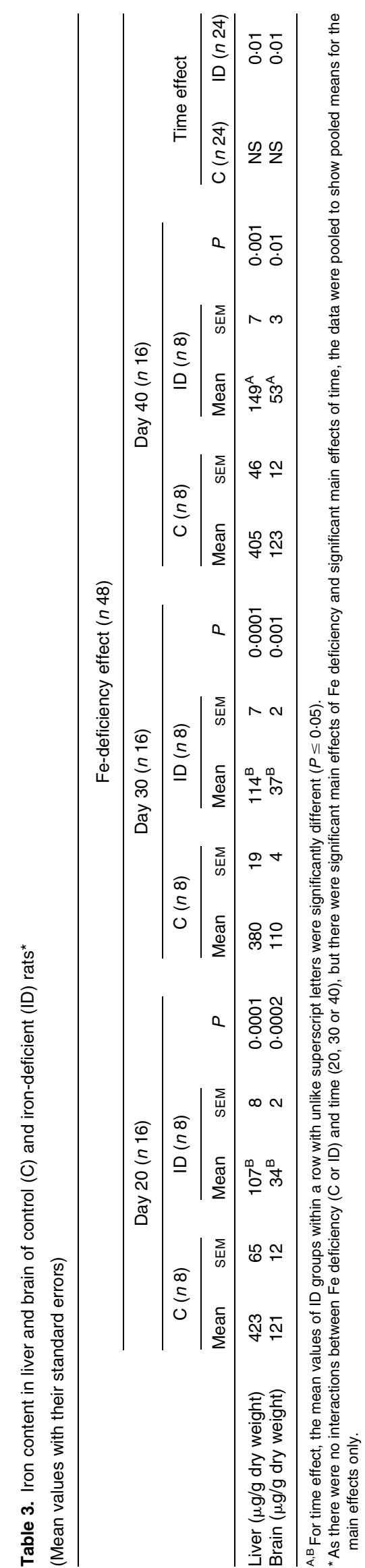



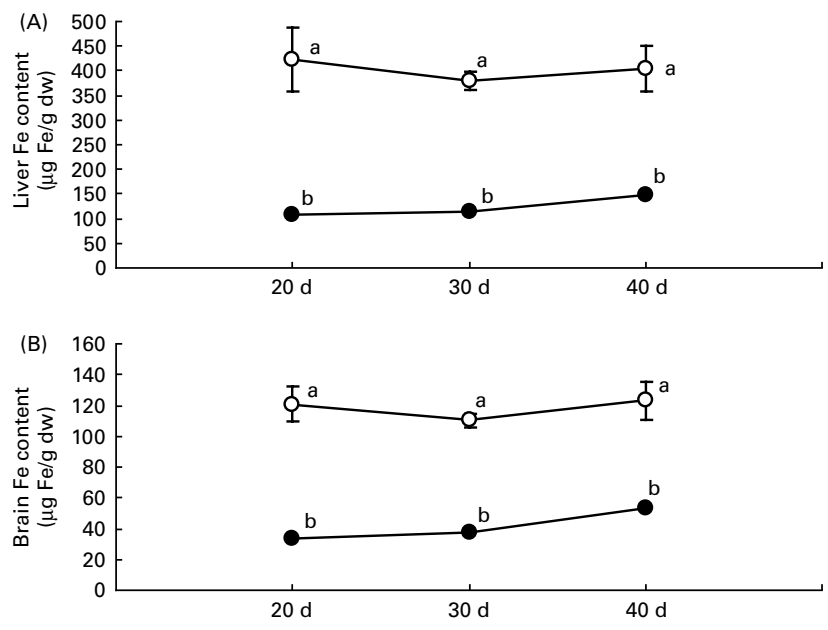

Fig. 1. Fe content in (A) liver and (B) brain over time $(20,30$ or $40 \mathrm{~d})$ $\mathrm{O}$, Control groups; $\bullet$, Fe-deficient groups. The means values with standard errors are represented by vertical bars. For details of groups, see Table 3 . The data were analysed by two-way ANOVA with repeated measures. There was a significant main effect for time and for Fe deficiency. There were no significant main effects for Fe-deficiency $\times$ time interaction. ${ }^{a, b}$ Mean values with unlike letters were significantly different $(P \leq 0.05)$. $d w$, Dry weight.

nutritive utilisation (ADC and $R / I$ ) in $\mathrm{C}$ rats was not modified in any of the studied periods. Nevertheless, in ID rats, the nutritive utilisation of $\mathrm{Fe}$ increased progressively in all the periods, this difference being statistically significant when comparing day 40 with day $20(P=0.009$ for ADC and $P=0.0048$ for $R / I$ ).

Table 3 summarises Fe concentrations in the liver and brain. Fe deposits in both the organs of ID rats were almost four times lower than in the $C$ group at day 20 of Fe deficiency, with values of 107 (SEM 8) v. 423 (SEM 65) $\mu \mathrm{g} \mathrm{Fe} / \mathrm{g}$ dry weight for liver (Fig. 1(A)) and 34 (SEM 2) $v$. 121 (sEm 12) $\mu \mathrm{g} \mathrm{Fe} / \mathrm{g}$ dry weight for brain (Fig. 1(B)). This lower Fe deposit remained at day $30(P=0.0009$ for the $\mathrm{C}$ group and $P=0.006$ for the ID group), but there was a slight recovery of the Fe content in the liver and brain at day $40(P=0.005)$ with regard to the previous periods (Fig. 1(A) and (B)).

Under the present experimental conditions, a decrease in SOD activities was observed in plasma $(P=0.01)$, together with CAT $(P=0.001)$ (Fig. 2(A)) and GPx $(P=0.05)$ (Fig. 2(B)) in hepatic cytosol of ID rats at day 20 of the study compared with the $\mathrm{C}$ rats, with no differences between the $\mathrm{C}$ and ID groups in the other studied periods (30 and $40 \mathrm{~d}$ ). Nevertheless, neither lipid peroxidation (TBARS) nor the studied mechanisms of antioxidant defence of SOD in plasma and CAT (Fig. 2(C)) and GPx (Fig. 2(D)) in the cytosolic fraction of brain and erythrocytes were altered by the Fe deficiency in any of the studied periods (Table 4).

\section{Discussion}

At the beginning of the study, all the haematological parameters studied were within the normal limits described
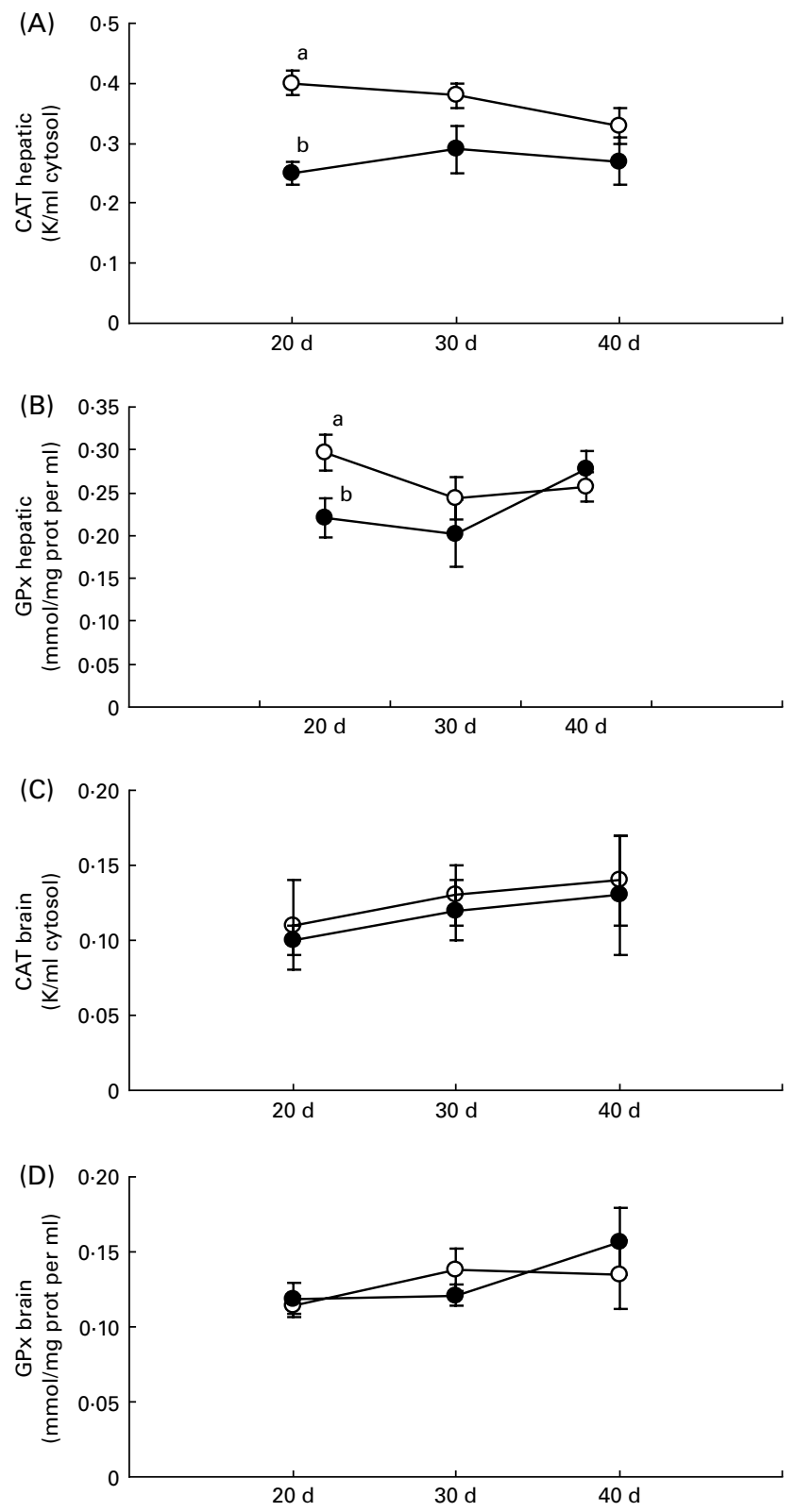

Fig. 2. Catalase (CAT) and glutathione peroxidase (GPx) activity in liver ((A) and (B)) and brain ((C) and (D)) over time (20,30 or $40 \mathrm{~d})$. $O$, Control groups; -, Fe-deficient groups. The means values with their standard errors are represented by vertical bars. For details of groups, see Table 4. The data were analysed by two-way ANOVA with repeated measures. There was a significant main effect for Fe deficiency. There were no significant main effects for time or Fe deficiency $\times$ time interaction. ${ }^{\mathrm{a}, \mathrm{b}}$ Mean values with unlike letters were significantly different $(P \leq 0.05)$. prot, Protein.

in the literature for this species at this age ${ }^{(21)}$. At day 20, the haematological parameters of the $\mathrm{C}$ rats were within normal limits, except for serum $\mathrm{Fe}$, as a consequence of the needs imposed by growth ${ }^{(22)}$ and of the increase of the demands of $\mathrm{Fe}$ for the synthesis of Fe-dependent enzymes $^{(23)}$. In ID rats, $\mathrm{Hb}$, erythrocytes, haematocrit, mean corpuscular volume, mean corpuscular $\mathrm{Hb}$ percentage saturation of transferrin and serum ferritin decreased in a marked way, whereas the platelets were higher. Fe deficiency is classified in three stages according to severity: 
Table 4. Antioxidant defence and thiobarbituric acid-reactive substances (TBARS) production in control (C) and iron-deficient (ID) rats* (Mean values with their standard errors)

\begin{tabular}{|c|c|c|c|c|c|c|c|c|c|c|c|c|}
\hline & \multicolumn{12}{|c|}{ Fe-deficiency effect $(n 48)$} \\
\hline & \multicolumn{4}{|c|}{ Day 20 (n 16) } & \multicolumn{4}{|c|}{ Day 30 (n 16) } & \multicolumn{4}{|c|}{ Day 40 (n 16) } \\
\hline & \multicolumn{2}{|c|}{$C(n 8)$} & \multicolumn{2}{|c|}{ ID $(n 8)$} & \multicolumn{2}{|c|}{$C(n 8)$} & \multicolumn{2}{|c|}{ ID $(n 8)$} & \multicolumn{2}{|c|}{$C(n 8)$} & \multicolumn{2}{|c|}{ ID $(n 8)$} \\
\hline & Mean & SEM & Mean & SEM & Mean & SEM & Mean & SEM & Mean & SEM & Mean & SEM \\
\hline SOD plasma (U/mg protein) & 2.49 & 0.08 & $2 \cdot 14^{\star \star}$ & 0.10 & $2 \cdot 35$ & 0.25 & 2.02 & 0.06 & $2 \cdot 62$ & 0.23 & $2 \cdot 36$ & 0.25 \\
\hline CAT hepatic ( $\mathrm{K} / \mathrm{ml}$ cytosol) & 0.40 & 0.02 & $0 \cdot 25^{\star * *}$ & 0.02 & 0.38 & 0.02 & 0.29 & 0.04 & 0.33 & 0.03 & 0.27 & 0.04 \\
\hline CAT brain $(\mathrm{K} / \mathrm{ml}$ cytosol) & 0.11 & 0.03 & $0 \cdot 10$ & 0.01 & 0.13 & 0.02 & $0 \cdot 12$ & 0.02 & 0.14 & 0.03 & $0 \cdot 13$ & 0.04 \\
\hline CAT erythrocyte (K/ml cytosol) & 0.21 & 0.03 & 0.23 & 0.02 & 0.20 & 0.03 & 0.21 & 0.04 & 0.21 & 0.06 & 0.20 & 0.03 \\
\hline GPx hepatic $(\mathrm{mmol} / \mathrm{mg}$ protein per $\mathrm{ml})$ & 0.30 & 0.02 & $0.22^{*}$ & 0.02 & 0.24 & 0.03 & 0.20 & 0.04 & 0.26 & 0.02 & 0.28 & 0.02 \\
\hline GPx brain $(\mathrm{mmol} / \mathrm{mg}$ protein per $\mathrm{ml})$ & 0.11 & 0.01 & 0.12 & 0.01 & 0.14 & 0.01 & 0.12 & 0.01 & 0.14 & 0.02 & $0 \cdot 16$ & 0.02 \\
\hline GPx erythrocyte $(\mathrm{mmol} / \mathrm{mg}$ protein per $\mathrm{ml})$ & 0.26 & 0.02 & $0 \cdot 30$ & 0.02 & 0.30 & 0.04 & 0.32 & 0.03 & 0.26 & 0.01 & 0.30 & 0.03 \\
\hline TBARS (nmol/mg protein) & 3.92 & 0.35 & $4 \cdot 39$ & 0.34 & 4.02 & 0.43 & 4.00 & 0.15 & $4 \cdot 32$ & 0.58 & 4.40 & 0.49 \\
\hline
\end{tabular}

SOD, superoxide dismutase activity; CAT, catalase activity; GPx, glutathione peroxidise activity.

Mean value was significantly different from that of the $C$ group: ${ }^{\star} P<0.05,{ }^{\star \star} P<0.01,{ }^{\star \star \star} P<0.001$

${ }^{\star}$ For the time effect, the data were analysed by one-way ANOVA, but there were no significant main effects.

depletion, marginal deficiency and anaemia. Depletion is characterised by depleted $\mathrm{Fe}$ stores with normal Fe-dependent protein production and normal Hb concentrations. Marginal deficiency is characterised by depleted Fe stores, reduced Fe-dependent protein production (e.g. oxidative enzymes) and normal $\mathrm{Hb}$ concentrations. Anaemia, the most severe form of deficiency, is characterised by depleted $\mathrm{Fe}$ stores, reduced $\mathrm{Hb}$ concentrations and reduced $\mathrm{Fe}$-dependent oxidative enzyme concentrations ${ }^{(23)}$. The drastic decrease of serum Fe, saturation of transferrin and serum ferritin, at day 20 can be owed not only to the needs imposed by growth but also to the consumption of a Fe-restrictive diet. The critical period in the development of nutritional Fe-deficiency anaemia happened between days 30 and 40, where there was a notable reduction in the weight gain and $\mathrm{Hb}$ concentration, together with a marked increase in the platelets, parameters that are indicative of the development of severe anaemia. The marked decrease of $\mathrm{Hb}$ levels and the other haematological parameters studied is due to the fact that the organism is unable to obtain Fe from body stores without compromising Fe-dependent enzymic mechanisms ${ }^{(23,24)}$.

The average initial weight of the rats was within the normal margins described in the literature of this species $^{(21,25)}$. The results of the present study have demonstrated that a parallelism exists at day 20 in the weight gain of both the groups of animals, $\mathrm{C}$ and ID, which indicates that Fe stored during the fetal period and during lactation is enough to cover the animals' needs in their early life stage. Because at day 40 , the concentration of $\mathrm{Hb}$, erythrocyte count and haematocrit were significantly reduced in ID animals, the supply of oxygen to the cells was lower, which had repercussions in a minor weight gain of this animal group. This is in agreement with the results found by Schneider et ll $^{(26)}$, reporting that in children $12-36$ months old, it is possible that low $\mathrm{Hb}$ concentrations limited the rate of weight gain, which would explain the association observed.

The nutritive utilisation of Fe found in ID rats increases progressively as Fe deficiency advances, and this can be due to the fact that this pathology produces a depletion of the body Fe stored ${ }^{(23)}$, which favours the uptake by simple diffusion following the gradient of concentration of this mineral ${ }^{(27)}$. In addition, in situations of $\mathrm{Fe}$ deficiency, the synthesis of divalent metal transporter 1 is increased $^{(28)}$ as well as the expression of ferroportin $1^{(29)}$. Therefore, these receptors favour the intestinal absorption of $\mathrm{Fe}$ in situations of deficiency of this mineral ${ }^{(30)}$.

According to Brownlie et al. ${ }^{(23)}$, Fe deficiency is characterised by depletion of Fe stores; however, in the present study, there was a slight recovery in the Fe content of the liver and brain at day 40 of the Fe deficiency in spite of the fact that these levels continue being two times below those found in $\mathrm{C}$ rats; this indicates the importance of this mineral during early life in both organs. The first years of life are critical for neurological development; the pace of neurological development in young children aged $0-4$ years is rapid, including critical periods of neural circuit formation and myelinisation in the brain. $\mathrm{Fe}$ in oligodendrocytes is required for proper myelinisation of the neurons used in the sensory system and learning and interacting behaviours ${ }^{(10)}$.

There is a controversy about the susceptibility of cells to lipid peroxidation in Fe deficiency: some authors argue that there is no difference in lipid peroxidation in ID patients compared to control ones ${ }^{(31,32)}$. Alexander et al. ${ }^{(6)}$ showed that reduced dietary $\mathrm{Fe}$ is considered to be beneficial in improving acute and chronic liver injuries by reducing oxidative stress. Other authors reported that while oxidants are increased, antioxidants are decreased and as a result, the oxidative/antioxidative balance shifted towards the oxidative side in patients with $\mathrm{Fe}$ deficiency ${ }^{(33,34)}$. Moreover, there is certain ambiguity in antioxidant enzyme status: 
some authors reported that antioxidant enzymes were low ${ }^{(35)}$ and others stated that antioxidant enzymes were increased in Fe-deficiency anaemia ${ }^{(36)}$. In the present study, as the levels of serum Fe were drastically diminished at day 20, keeping these low levels during the progression of anaemia, it is logical to think once again that the decrease in serum $\mathrm{Fe}$ is translated into a minor production of reactive oxygen species, which might explain the decrease in SOD in the plasma compartment at day 20. TBARS production was similar in $\mathrm{C}$ and ID rats, suggesting once again that the total antioxidant capacity of the organism is adapted in the course of the development of anaemia, due to the adequate activities of the antioxidant enzymes CAT, GPx and SOD that are involved in the reduction of the peroxides, which can attack PUFA, therefore avoiding lipid peroxidation and the subsequent formation of TBARS. Rats at birth have a high level of serum Fe, but during the first weeks of life many erythrocytes haemolyse, in a physiological process to normalise the high erythrocyte count featured at this point. The Fe that is liberated is stored principally in the liver and the spleen. Since the mother' milk is a poor source of $\mathrm{Fe}$, this is used during the first days of life for helping to synthesise $\mathrm{Hb}$ and increase the number of erythrocytes, a fact that becomes extremely important as the animal grows, to satisfy the demands of oxygen and oxidative metabolism. Fe stored in the newborn animal together with the low amount that is supplied from the mother's milk is sufficient for a short period of time, but from this moment it is necessary that the diet provides a suitable level of $\mathrm{Fe}^{(37,38)}$. In the present study, because $\mathrm{Fe}$ deficiency had been induced in growing rats, the excess of serum Fe which the animals had at birth was not stored, but was used in an unsuccessful attempt to replete body $\mathrm{Fe}$, trying to maintain the serum levels within physiological range. Due to the fact that the ID animals had a minor content of hepatic Fe in all the periods studied compared with the $\mathrm{C}$ animals, especially at day 20 of the Fe deficiency, this can be the reason why a decrease was observed in the activities of CAT and GPx, since Fe deficiency would exert a protective effect avoiding the generation of reactive oxygen species (especially hydroxyl radicals via Fenton and Haber-Weiss chemistry) ${ }^{(39)}$. Nevertheless, in spite of the low Fe stores in the brain of ID rats, two to three times lower compared with those in the $\mathrm{C}$ rats, especially at day 20 , changes were not observed in the activity of the antioxidant enzymes CAT and GPx by Fe deficiency in any of the periods studied. CAT is a ferric haeme-containing enzyme. Fe deficiency can reduce the activity of Fe-dependent enzymes ${ }^{(40)}$; however, under our experimental conditions, CAT activity in the brain cytosolic fraction among ID and $\mathrm{C}$ rats did not differ.

\section{Acknowledgements}

This work was supported by The Inter Ministerial Commission of Science and Technology (CICYT) Research Project no. AGL-2006-02301/ALI. The authors are grateful to the University of Granada for the personal support of J. D.-C. and to Ms Elisa Alcover for her efficient administrative support. M. S. C. designed and conducted the study, analysed the data and wrote the manuscript; M. J. M. A., I. L.-A. and J. D.-C. performed experiments, data collection, statistical analysis and wrote the manuscript. M. R.-F. and L. J. P.-S. collaborated in the enzyme analysis. All authors declare that they have no conflicts of interest.

\section{References}

1. Leung AKC \& Chan KW (2001) Fe deficiency anemia. Adv Pediatr 48, 385-408.

2. Lozoff B, Beard J, Connor J, et al. (2006) Long-lasting neural and behavioral effects of iron deficiency in infancy. Nutr Rev 64, S34-S43.

3. Rao R \& Georgieff MK (2007) Iron in fetal and neonatal nutrition. Semin Fetal Neonatal Med 12, 54-63.

4. World Health Organization (2002) Reducing Risks, Promoting Healthy Life. The World Health Report 2002. Geneva: World Health Organization.

5. American Academy of Pediatrics Committee on Nutrition (2004) Iron deficiency. In Pediatric Nutrition Handbook, pp. 299-312 [RE Kleinman, editor]. Elk Grove Village, IL: American Academy of Pediatrics.

6. Alexander J, Tung BY, Croghan A, et al. (2007) Effect of iron depletion on serum markers of fibrogenesis, oxidative stress and serum liver enzymes in chronic hepatitis C: results of a pilot study. Liver Int 27, 268-273.

7. Beard J (2003) Iron deficiency alters brain development and functioning. J Nutr 133, 1468S-1472S.

8. Beard JL, Wiesinger JA \& Connor JR (2003) Pre- and postweaning iron deficiency alters myelination in SpragueDawley rats. Dev Neurosci 25, 308-315.

9. Ortiz E, Pasquini JM, Thompson K, et al. (2004) Effect of manipulation of iron storage, transport, or availability on myelin composition and brain iron content in three different animal models. J Neurosci Res 77, 681-689.

10. Lozoff B \& Black MM (2004) Impact of micronutrient deficiencies on behavior and development. In Micronutrient Deficiencies During the Weaning Period and the First Years of Life, pp. 19-35 [JM Pettifor and S Zlotkin, editors]. Basel: Nestec Ltd.

11. Beard JL \& Connor JR (2003) Fe status and neural functioning. Annu Rev Nutr 23, 31-58.

12. Reeves PG, Nielsen FH \& Fahey GC (1993) AIN-93 purified diets for laboratory rodents: final report of the American Institute of Nutrition and $A d$ hoc Writing Committee on the reformulation of the AIN-76A rodent diet. J Nutr 123, 1939-1951.

13. Pallarés I, Lisbona F, López-Aliaga I, et al. (1993) Effects of iron deficiency on the digestive utilization of iron, phosphorus, calcium and magnesium in rats. BrJ Nutr 70, 609-620.

14. Hanahan DJ \& Ekholm JE (1974) The preparation of red cell ghost (membranes). Methods Enzymol 31, 168-172.

15. Lowry OH, Rosenburgh NJ, Farr AL, et al. (1951) Protein measurement with folin phenol reagent. J Biol Chem 193, 265-270.

16. Yagi K (1976) A simple fluorometric assay for lipoperoxide in blood plasma. Biochem Med 15, 212-216.

17. Ohkawa H, Ohishi N \& Yagi K (1979) Assay for lipid peroxides in animal tissues by thiobarbituric acid reaction. Anal Biochem 95, 351-358. 
18. Aebi H (1984) Catalase in vitro. Methods Enzymol 150 121-127.

19. Crapo JD, McCord JM \& Fridovich I (1978) Preparation and assay of superoxide dismutases. Methods Enzymol $\mathbf{5 3}$, 382-393.

20. Flohé L \& Gunzler WA (1984) Assays of glutathione peroxidase. Methods Enzymol 105, 114-121.

21. Campos MS, Barrionuevo M, Alférez MJM, et al. (1998) Interactions among iron, phosphorus, calcium and magnesium in nutritionally iron-deficient rats. Exp Physiol 83, 771-781.

22. Olivares M, Walter T, Cook JD, et al. (2000) Usefulness of serum transferrin receptor and serum ferritin in diagnosis of iron deficiency in infancy. Am J Clin Nutr 72, 1191-1195.

23. Brownlie T, Utermohlen V, Hinton PS, et al. (2002) Marginal iron deficiency without anemia impairs aerobic adaptation among previously untrained women. Am J Clin Nutr 75, $734-742$.

24. Zimmermann MB, Chaouki N \& Hurrell RF (2005) Iron deficiency due to consumption of a habitual diet low in bioavailable iron: a longitudinal cohort study in Moroccan children. Am J Clin Nutr 81, 115-121.

25. Krinke GJ (2000) History, strains and models. In The Laboratory Rat (Handbook of Experimental Animals), pp. 3-16, GR Bullock (series ed.) [T Bunton, editor]. London: Academic Press.

26. Schneider JM, Fujii ML, Lamp CL, et al. (2008) The use of multiple logistic regression to identify risk factors associated with anemia and iron deficiency in a convenience sample of 12-36-mo-old children from low-income families. Am J Clin Nutr 87, 614-620.

27. Gómez-Ayala AE, Lisbona F, López-Aliaga I, et al. (1998) The absorption of iron, calcium, phosphorus, magnesium, copper and zinc in the jejunum-ileum of control and irondeficient rats. Lab Animal 32, 72-79.

28. Yeh KY, Yeh M, Watkins A, et al. (2000) Dietary iron induces rapid changes in rat intestinal divalent metal transporter expression. Am J Physiol Gastrointest Liver Physiol 279 G1070-G1079.

29. Morgan EH \& Oates PS (2002) Mechanisms and regulation of intestinal iron absorption. Blood Cells Mol Dis 29, 384-399.

30. Forellat M, Gautier H \& Fernández N (2000) Metabolismo del hierro. Rev Cub Hematol Inmunol Hemoter 16, 149-160.

31. Acharya J, Punchard NA, Taylor IA, et al. (1991) Red cell peroxidation and antioxidant enzymes in iron deficiency. Eur J Haematol 47, 287-291.

32. Isler M, Delibas N, Guclu M, et al. (2002) Superoxide dismutase and glutathione peroxidase in erythrocytes of patients with iron deficiency anemia: effects of different treatment modalities. Coat Med J 43, 16-19.

33. Kumerova A, Lece A, Skesters A, et al. (1998) Anaemia and antioxidant defence of the red blood cells. Mater Med Pol 30, 2-15.

34. Aslan M, Horoz M, Kocyigit A, et al. (2006) Lymphocyte DNA damage and oxidative stress in patients with iron deficiency anemia. Mutat Res 601, 144-149.

35. Yoo JH, Maeng HY, Sun YK, et al. (2009) Oxidative status in iron-deficiency anemia. J Clin Lab Anal. 23, 319-323.

36. Coghetto Baccin A, Lauerman Lazzaretti L \& Duarte Martins Brandao V (2009) Oxidative stress in older patients with iron deficiency anaemia. J Nutr Health Aging 13, 666-670.

37. Iannotti LL, Tielsch JM, Black MM, et al. (2006) Iron supplementation in early childhood: health benefits and risks. Am J Clin Nutr 84, 1261-1276.

38. Domellöf M, Hernell O, Abrams SA, et al. (2009) Iron supplementation does not affect copper and zinc absorption in breastfed infants. Am J Clin Nutr 89, 185-190.

39. Tanaka N \& Kiyosawa K (2004) Phlebotomy: a promising treatment for chronic hepatitis C. J Gastroenterol 39, 601-603.

40. Hess SY, Zimmermann MB, Arnold M, et al. (2002) Irondeficiency anemia reduces thyroid peroxidase activity in rats. J Nutr 132, 1951-1955. 